\title{
Irreversible Capacity and Lithium-ion Insertion/Extraction Kinetics of a High Potential Negative Electrode $\mathrm{TiO}_{2}(\mathrm{~B})$
}

\author{
Yosuke Murota, Yasuyuki Oba, Mikihiro Takagi, Takayuki Asao, Morihiro Saito, \\ Akimasa TASAKA, and Minoru InABA*
}

\begin{abstract}
Department of Molecular Chemistry and Boichemistry, Faculty of Science and Engineering, Doshisha University
\end{abstract} (Kyotanabe, Kyoto 610-0321, Japan)

Received December 3, 2009 ; Accepted January 15, 2010

\begin{abstract}
$\mathrm{Li}^{+}$ion insertion/extraction properties of $\mathrm{TiO}_{2}(\mathrm{~B})$ powder, which was prepared from a $\mathrm{K}_{2} \mathrm{Ti}_{4} \mathrm{O}_{9}$ precursor by ionexchange and dehydration, was investigated as a high-potential negative electrode. The irreversible capacity greatly decreased from $124 \mathrm{mAh} \mathrm{g}^{-1}$ to $c a .40 \mathrm{mAh} \mathrm{g}^{-1}$ when the lower potential limit was raised from $1.0 \mathrm{~V}$ to $E \geq 1.2$ $\mathrm{V}$, which indicated that the irreversible capacity mainly originated from surface reactions, such as solvent decomposition, at $E \leq 1.2 \mathrm{~V}$ in the first cycle. In galvanostatic intermittent titration tests, large polarization was observed at the beginning and the end of charging. This clearly indicated that a slow process is involved in the insertion reaction at the beginning and the end of charging, which causes solvent decomposition at potentials lower than 1.4 V. The reversible capacity was greatly improved to 246 and $276 \mathrm{mAh} \mathrm{g}^{-1}$ at an elevated temperature of $60^{\circ} \mathrm{C}$ and at a lower rate of $\mathrm{C} / 60$, respectively. The $\mathrm{TiO}_{2}(\mathrm{~B})$ sample contained $c a .14 \mathrm{wt} \%$ of the anatase phase as an impurity, and a reduction of the anatase phase was found to be effective for an increase in reversible capacity at moderate charge/discharge rates.
\end{abstract}

Key Words : $\mathrm{TiO}_{2}(\mathrm{~B})$, High Potential Negative Electrode, Irreversible Capacity, Cycleability

\section{Introduction}

Recently, large-size lithium-ion batteries (LIBs) have been intensively developed for use in electric vehicles and energy storage systems. However, there remain serious problems, such as safety, durability, and cost, to be solved before commercialization of large-size LIBs..1) The use of high potential negative electrodes working at potentials $>1.0 \mathrm{~V}$ vs. $\mathrm{Li} / \mathrm{Li}^{+}$is one of the methods for solving these issues. It has recently reported that nanowires ${ }^{2-4)}$ and nanotubes ${ }^{5-7)}$ of $\mathrm{TiO}_{2}(\mathrm{~B})$ prepared by hydrothermal treatment have a high capacity of 200-300 $\mathrm{mAh} \mathrm{g}^{-1}$ at about $1.6 \mathrm{~V}$ vs. $\mathrm{Li}^{-} \mathrm{Li}^{+}$with good cycleability. ${ }^{2,3)}$ However, the hydrothermal process is not suitable for mass production, which raises the material cost of $\mathrm{TiO}_{2}(\mathrm{~B})$. From this viewpoint, we have prepared $\mathrm{TiO}_{2}(\mathrm{~B})$ powder from a $\mathrm{K}_{2} \mathrm{Ti}_{4} \mathrm{O}_{9}$ precursor, which was synthesized by a solid-state reaction, and investigated charge/discharge characteristics of the $\mathrm{TiO}_{2}(\mathrm{~B})$ powder as a high potential negative electrode in LIBs. ${ }^{8}$ It had a high discharge capacity of 200-250 $\mathrm{mAh} \mathrm{g}^{-1}$ at around 1.6 $\mathrm{V}$ vs. $\mathrm{Li} / \mathrm{Li}^{+}$, though the capacity was lower than its theoretical capacity $\left(335 \mathrm{mAh} \mathrm{g}^{-1}\right)$. It also showed very good cycleability, and gave a discharge capacity of $171.5 \mathrm{mAh}$ $\mathrm{g}^{-1}$ even after 650 cycles (1.0-3.0 V). However, the sample had a high irreversible capacity of $123.0 \mathrm{mAh} \mathrm{g}^{-1}$ in the first cycle. It is therefore necessary to reduce the irreversible capacity as well as to further improve the capacity close to the theoretical capacity $\left(335 \mathrm{mAh} \mathrm{g}^{-1}\right)$.

In the present study, $\mathrm{Li}^{+}$ion insertion/extraction properties of $\mathrm{TiO}_{2}(\mathrm{~B})$ were investigated in detail to understand the origin of the irreversible capacity and rate-lim- iting processes involved in the charge and discharge reactions.

\section{Experimental}

$\mathrm{K}_{2} \mathrm{CO}_{3}$ (Wako Pure Chemicals, 99.8\%) and anatase $\mathrm{TiO}_{2}$ (Wako Pure Chemicals, 99.9\%, average diameter: 20 $\mathrm{nm}$ ) were mixed in a molar ratio of $1: 4$, and calcined twice at $1000{ }^{\circ} \mathrm{C}$ for $24 \mathrm{~h}$ to obtain $\mathrm{K}_{2} \mathrm{Ti}_{4} \mathrm{O}_{9}$ powder as a precursor. The $\mathrm{K}_{2} \mathrm{Ti}_{4} \mathrm{O}_{9}$ powder was washed with highly pure water, and was immersed in $1 \mathrm{M} \mathrm{HCl}$ for 3 days to exchange the $\mathrm{K}^{+}$ions to protons. The resulting protonated powder was dehydrated at $500{ }^{\circ} \mathrm{C}$ for 30 min to obtain $\mathrm{TiO}_{2}(\mathrm{~B})$. The powder sample was analyzed by X-ray diffraction (XRD, Rigaku, RINT2000) and field-emission scanning electron microscopy (FE-SEM, JEOL, JSM7001FD). The content of the anatase phase in the $\mathrm{TiO}_{2}(\mathrm{~B})$ sample was determined by an internal standard method, in which $\mathrm{CaCO}_{3}$ and $\mathrm{NiO}$ were used as an internal standard substance and as a diluent agent, respectively. The calibration line was obtained from the ratio of the (101) line of the anatase phase and the (104) line of $\mathrm{CaCO}_{3}$ using the mixtures of anatase $\mathrm{TiO}_{2}$ (Merck, $99.9 \%$ ) and $\mathrm{CaCO}_{3}$ (Wako Pure Chemicals, reagent grade) powder of different compositions.

The $\mathrm{TiO}_{2}(\mathrm{~B})$ powder was mixed with Ketjen Black (KB, Lion Corp., EC600JD) and poly(vinylidene fluoride) (Kureha, KF Polymer) at a weight ratio of 8:1:1, using 1methyl-2-pyrrolidinone (Wako Pure Chemicals, reagent grade) as a solvent, to make a viscous slurry. The slurry was coated on a copper foil current collector $\left(0.785 \mathrm{~cm}^{2}\right)$ with a thickness of $100 \mu \mathrm{m}$, and then dried overnight at 
$80^{\circ} \mathrm{C}$ under vacuum. The loading of the electrode material was $c a .1 .5 \mathrm{mg} \mathrm{cm}^{-2}$. The electrolyte solution was either $1.0 \mathrm{M} \mathrm{LiClO}_{4}$ dissolved in a 1:1 mixture (by volume) of ethylene carbonate (EC) and diethyl carbonate (DEC) or 1.0 M LiPF 6 EC + DEC (1:1). A coin-type twoelectrode half cell was constructed from the $\mathrm{TiO}_{2}(\mathrm{~B})$ electrode, a separator (Celgard ${ }^{\circledR}$ 2326) and a lithium-foil counter electrode (Honjo Metal) in argon-filled glove box (Miwa, MDB- 1B + MM3-P60S) with a dew point lower than $-60{ }^{\circ} \mathrm{C}$. Charge and discharge characteristics were measured at a $\mathrm{C} / 6$ rate between $1.0 \mathrm{~V}$ and $3.0 \mathrm{~V}$ at $30^{\circ} \mathrm{C}$, unless otherwise noted, using a battery test system (Hokuto Denko, HJ1001SM8). In the present study, lithium-ion insertion into and extraction from $\mathrm{TiO}_{2}(\mathrm{~B})$ are denoted as charging and discharging, respectively, considering the role of $\mathrm{TiO}_{2}(\mathrm{~B})$ as a negative electrode in LIBs.

The variation of open-circuit potential (OCP) during charging and discharging was measured using the galvanostatic intermittent titration technique (GITT). The electrode was charged or discharged by $x=0.05$ in $\mathrm{Li}_{x} \mathrm{TiO}_{2}(\mathrm{~B})$ at a $\mathrm{C} / 6$ rate, and was left for $24 \mathrm{~h}$ under open-circuit conditions to measure OCP. This procedure was repeated until the potential reached 1.0 or $3.0 \mathrm{~V}$ on charging and discharging, respectively.

\section{Results and Discussion}

Figure 1 shows the XRD pattern for the synthesized $\mathrm{TiO}_{2}(\mathrm{~B})$ powder. The formation of the $\mathrm{TiO}_{2}(\mathrm{~B})$ phase (JCPDS 35-0088) was confirmed after the dehydration process. Unfortunately, the $\mathrm{TiO}_{2}(\mathrm{~B})$ powder was not a single phase, but contained a considerable amount (14 wt $\%$ ) of the anatase phase, which was probably formed in the final dehydration process at $500{ }^{\circ} \mathrm{C} .^{9}$

SEM images of the $\mathrm{TiO}_{2}(\mathrm{~B})$ powder are shown in Fig. 2. The powder has a needle-like structure with a diameter of $c a .250 \mathrm{~nm}$ and a length of $c a .2 \mu \mathrm{m}$. The shape, needle-like structure, is characteristic of the $\mathrm{K}_{2} \mathrm{Ti}_{4} \mathrm{O}_{9}$ precursor, and did not change appreciably after the ion exchange and dehydration processes. Hence the shape of $\mathrm{TiO}_{2}(\mathrm{~B})$ is determined in the first calcination process.

Figure 3 shows the charge/discharge curves of the $\mathrm{TiO}_{2}$ (B) powder at $30{ }^{\circ} \mathrm{C}$ in $1 \mathrm{M} \mathrm{LiClO}_{4} / \mathrm{EC}+\mathrm{DEC}(1: 1)$. The $\mathrm{TiO}_{2}(\mathrm{~B})$ powder gave a high discharge capacity of ca. $250 \mathrm{mAh} \mathrm{g}^{-1}$ with a slightly sloping plateau at around 1.6 $\mathrm{V}$ on the charge and discharge curves, which are similar to those reported for $\mathrm{TiO}_{2}(\mathrm{~B})$ nanowire ${ }^{2-4)}$ and nanotubes. ${ }^{57)}$ The initial discharge capacity of $246 \mathrm{mAh} \mathrm{g}^{-1}$ is higher than that of $\mathrm{Li}_{4} \mathrm{Ti}_{5} \mathrm{O}_{12}$, ${ }^{10-12)}$ and comparable with those of $\mathrm{TiO}_{2}(\mathrm{~B})$ nanowires and nanotubes. On the other hand, a considerably high irreversible capacity (123 $\mathrm{mAh}^{-1}$ ) was observed in the first cycle, but disappeared in the second and subsequent cycles. After an initial drop in discharge capacity, high discharge capacities of $c a .200$

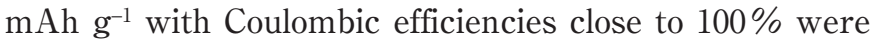
stably obtained in prolonged cycles. ${ }^{8)}$ The discharge capacity as high as $170 \mathrm{mAh} \mathrm{g}^{-1}$ was obtained even in the 650th cycle as shown in Fig. 3. The good cycleability indicates a high structural integrity of $\mathrm{TiO}_{2}(\mathrm{~B})$, though it is a metastable phase.
One of the drawbacks of $\mathrm{TiO}_{2}(\mathrm{~B})$ is the high irreversible capacity in the first cycle as described above. To understand the origin of the irreversible capacity, we investigate the effect of the lower potential limit in charge and discharge tests. Figure 4 shows charge/discharge curves of the $\mathrm{TiO}_{2}(\mathrm{~B})$ in various potential ranges of (a) 1.6-3.0, (b) 1.4-3.0, (c) 1.2-3.0, and (d) 0.8-3.0 V vs. $\mathrm{Li} / \mathrm{Li}^{+}$in $1.0 \mathrm{M} \mathrm{LiClO}_{4} / \mathrm{EC}+\operatorname{DEC}(1: 1)$. In all cases, the irreversible capacity was observed only in the first cycle, but disappeared in the second and subsequent cycles. The irreversible capacity in the first cycle was high $(>$ $100 \mathrm{mAh}^{-1}$ ) when the lower potential limit was set at $1.0 \mathrm{~V}$ (see Fig. 3) or lower, but was greatly reduced to $c a$. $40 \mathrm{mAh} \mathrm{g}^{-1}$ when the lower potential limit was set at 1.2 $\mathrm{V}$ or higher. Lower discharge rates did not appreciably reduce the irreversible capacity (not shown), and hence the high irreversible capacity is not due to slow kinetics in the extraction of $\mathrm{Li}^{+}$ions. It is therefore considered that the high irreversible capacity mainly originated from surface reactions, such as solvent decomposition at potentials $\leq 1.2 \mathrm{~V}$. As shown in Fig. 4, the cycleability was also improved when the lower potential limit was set at potentials $\geq 1.2 \mathrm{~V}$, which may be due to suppression of solvent decomposition. From standpoints of irreversible capacity and cycleability, the lower potential limit should be set at $1.2 \mathrm{~V}$ or higher; however, raising

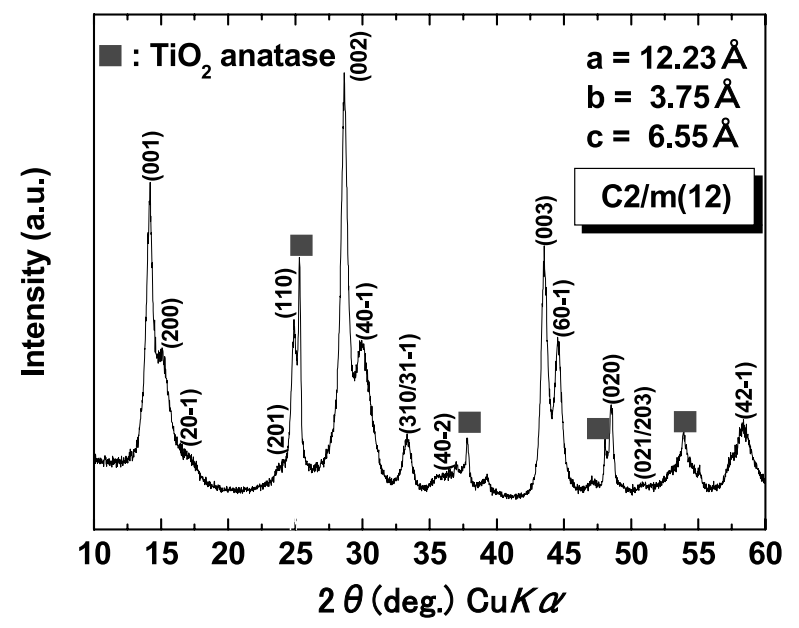

Fig. 1 XRD patterns of the synthesized $\mathrm{TiO}_{2}(\mathrm{~B})$ powder.

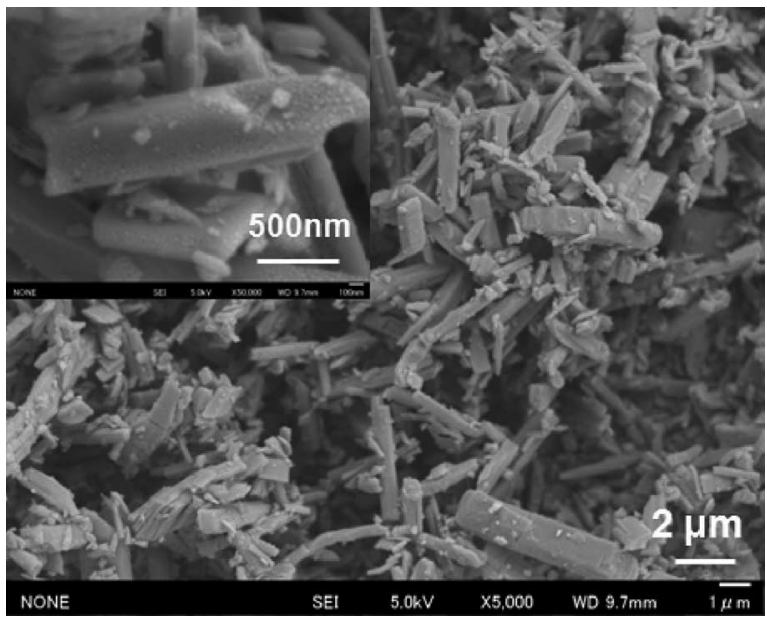

Fig. 2 SEM images of $\mathrm{TiO}_{2}(\mathrm{~B})$ particles. 
the lower potential limit from $1.0 \mathrm{~V}$ to $1.2-1.4 \mathrm{~V}$ resulted in a reduced capacity of $c a .170 \mathrm{mAh} \mathrm{g}^{-1}$.

The rate-limiting processes in the charge and discharge reactions of $\mathrm{TiO}_{2}(\mathrm{~B})$ were investigated using GITT. Figure 5 shows the variations of open-circuit potential (OCP) during intermittent charging and discharging at $\mathrm{C} / 6$ in the second cycle. On the galvanostatic intermittent titration curves, large polarization was observed at the beginning and the end of charging. It is widely known that $\mathrm{Ti}(\mathrm{IV}) \mathrm{O}_{2}$ is an insulator, but introduction of $\mathrm{Ti}^{3+}$ ions by $\mathrm{Li}^{+}$insertion greatly improves the electronic conductivity of lithiated $\mathrm{Li}_{x} \mathrm{TiO}_{2}$. However, when the average valence of $\mathrm{Ti}$ ions falls down below 3.5, the electronic conductivity would drop sharply as was reported for the Magneli phase $\mathrm{Ti}_{\mathrm{n}} \mathrm{O}_{2 \mathrm{n}-1 .}{ }^{13)}$ Hence the large polarization was attributed to low electronic conductivity of $\mathrm{Ti}(\mathrm{IV}) \mathrm{O}_{2}(\mathrm{~B})$ and $\mathrm{LiTi}(\mathrm{III}) \mathrm{O}_{2}$, which appear at the beginning and the end of charging, respectively.

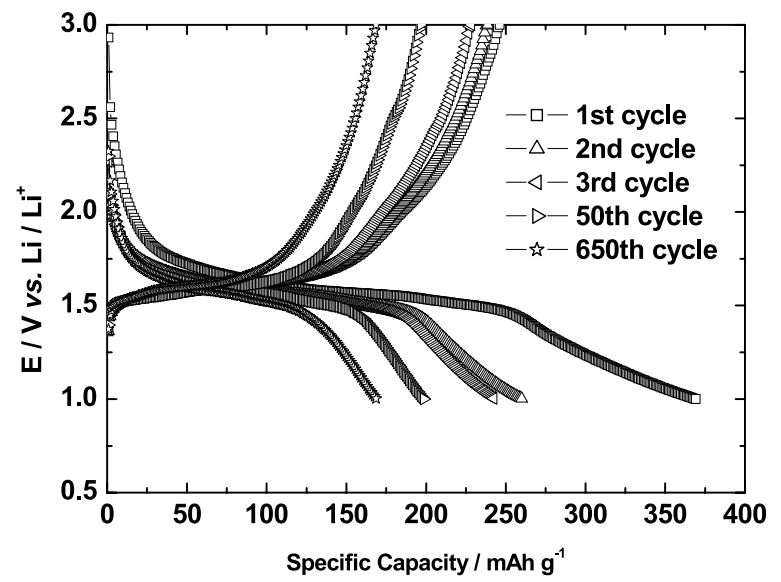

Fig. 3 Charge and discharge curves of $\mathrm{TiO}_{2}(\mathrm{~B})$ in $1 \mathrm{M}$ $\mathrm{LiClO}_{4} / \mathrm{EC}+\mathrm{DEC}(1: 1)$. Potential range: $1.0-3.0 \mathrm{~V}$ vs. $\mathrm{Li} / \mathrm{Li}^{+}$.
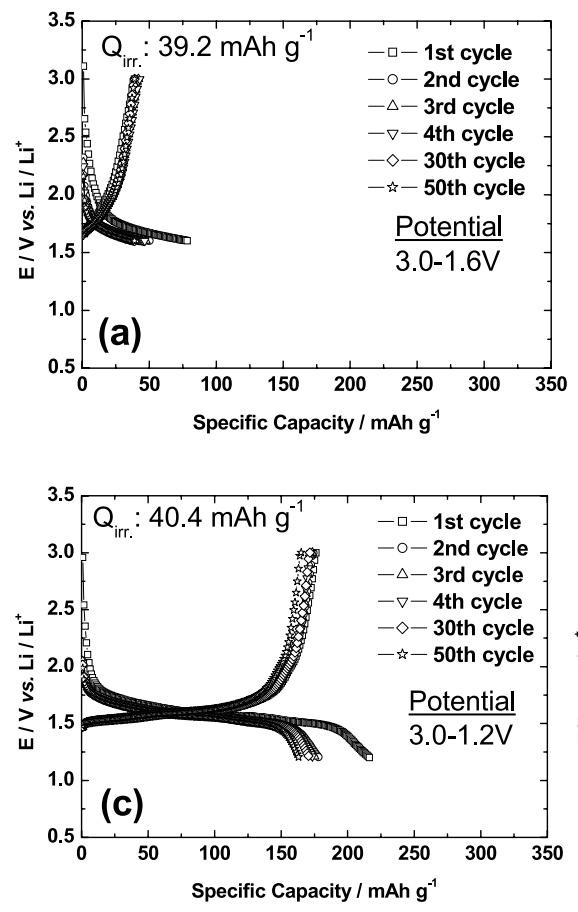

Another plausible reason for the large polarization is a lack of available sites for $\mathrm{Li}^{+}$ions in the lattice to move, especially at the end of charging. It should be noted that the OCP was never lower than $1.4 \mathrm{~V}$ even at the end of charging. This clearly indicates that the large polarization at the end of charging causes irreversible surface reactions, such as solvent decomposition, which led to the high irreversible capacity when the lower potential limit was set at $1.0 \mathrm{~V}$ or lower shown in Figs. 3 and 4.

Figures 6(a) and (b) show the charge/discharge curves of $\mathrm{TiO}_{2}(\mathrm{~B})$ at an elevated temperature and at a slower rate, respectively, between 1.4 and $3.0 \mathrm{~V}$ in $1.0 \mathrm{M} \mathrm{LiPF}_{6}$ dissolved in EC + DEC (1:1). As shown in Fig. 4(b), the discharge capacity was $167 \mathrm{mAh} \mathrm{g}^{-1}$ at $\mathrm{C} / 6$ and $30^{\circ} \mathrm{C}$. In contrast, it increased greatly at an elevated temperature $\left(246 \mathrm{mAh} \mathrm{g}^{-1}\right.$ at $\left.60^{\circ} \mathrm{C}\right)$ and at a lower rate $\left(267 \mathrm{mAh} \mathrm{g}^{-1}\right.$

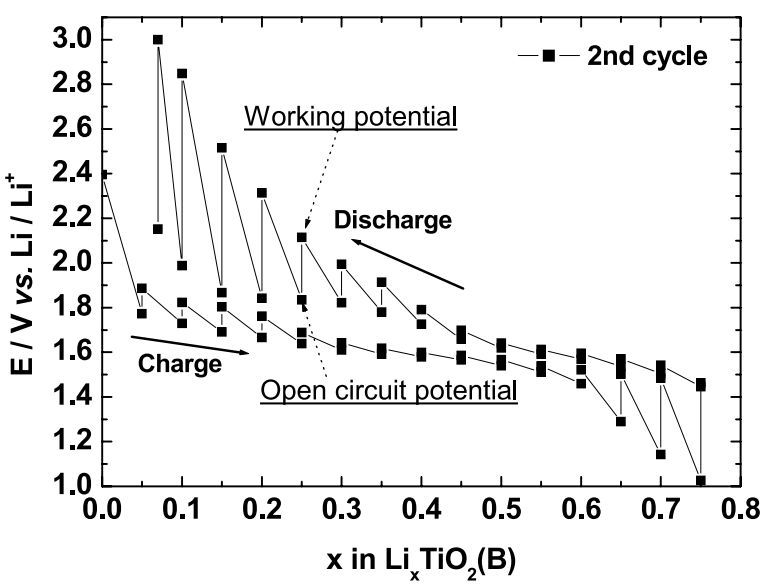

Fig. 5 Variation of open-circuit voltage of $\mathrm{TiO}_{2}(\mathrm{~B})$ as a function of $x$ in $\mathrm{Li}_{x} \mathrm{TiO}_{2}(\mathrm{~B})$ in the 2nd cycle in $1 \mathrm{M}$ $\mathrm{LiPF}_{6} / \mathrm{EC}+\mathrm{DEC}(1: 1)$ at $\mathrm{C} / 6$. Each intermittence time was $24 \mathrm{~h}$.
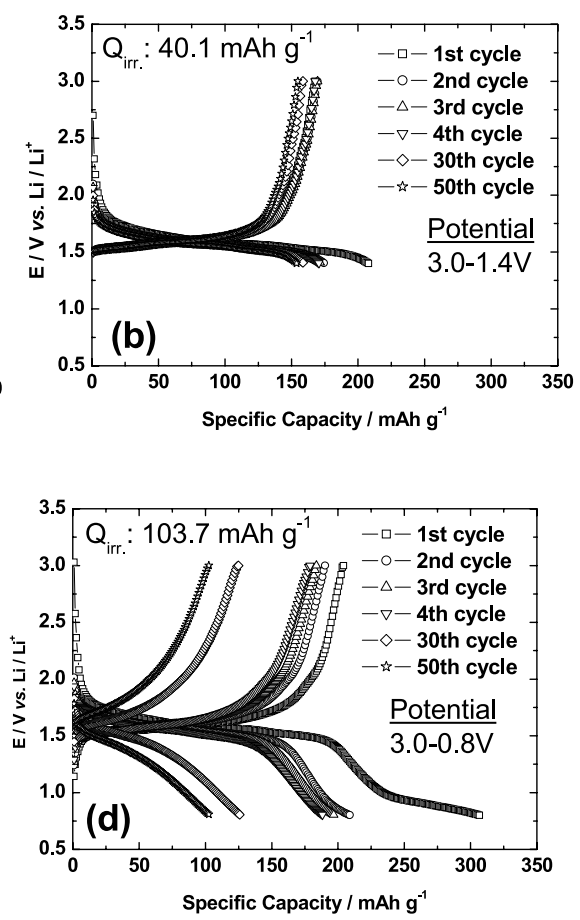

Fig. 4 Charge and discharge curves of $\mathrm{TiO}_{2}(\mathrm{~B})$ in various potential ranges in $1 \mathrm{M} \mathrm{LiClO} / \mathrm{EC}+\mathrm{DEC}(1: 1)$. Potential range: (a) 1.6-3.0 V, (b) 1.4-3.0 V, (c) 1.2-3.0 V and (d) 0.8-3.0 V vs. Li/ $\mathrm{Li}^{+}$. 
at $\mathrm{C} / 60$ ). These facts show that the reversible capacity is limited by a slow process at the end of charging as mentioned above. Hence accelerating the $\mathrm{Li}^{+}$insertion rate at the end of charging is important to improve the reversible capacity close to the theoretical capacity (335 $\left.\mathrm{mAh} \mathrm{g}^{-1}\right)$. In addition, an obscure potential plateau appeared at $c a$. $1.8 \mathrm{~V}$ vs. $\mathrm{Li} / \mathrm{Li}^{+}$on the charge and discharge curves in Fig. 6(b). The potential plateau is attributed to the $\mathrm{Li}^{+}$insertion into and extraction from the anatase phase, in which the $\mathrm{Li}^{+}$diffusion rate is much slower than that in $\mathrm{TiO}_{2}(\mathrm{~B}){ }^{14)}$ As shown in Fig. 1, our $\mathrm{TiO}_{2}(\mathrm{~B})$ sample contains a considerable amount $(14 \%)$ of the anatase phase. It is therefore considered that the reversible capacity also can be improved by decreasing the amount of the anatase phase.

It should be noted that the irreversible capacity increased to $c a$. $100 \mathrm{mAh} \mathrm{g}^{-1}$ at an elevated temperature $\left(60^{\circ} \mathrm{C}\right)$ in Fig. 6(a). This fact implies that solvent decomposed even at potential higher than $1.4 \mathrm{~V}$, which was enhanced by raising the temperature. Further investigation on solvent decomposition and the resulting surface film formation is necessary for minimizing the irreversible capacity and improving cycleability at elevated temperatures.

\section{Conclusions}

A $\mathrm{TiO}_{2}(\mathrm{~B})$ powder sample was prepared from a
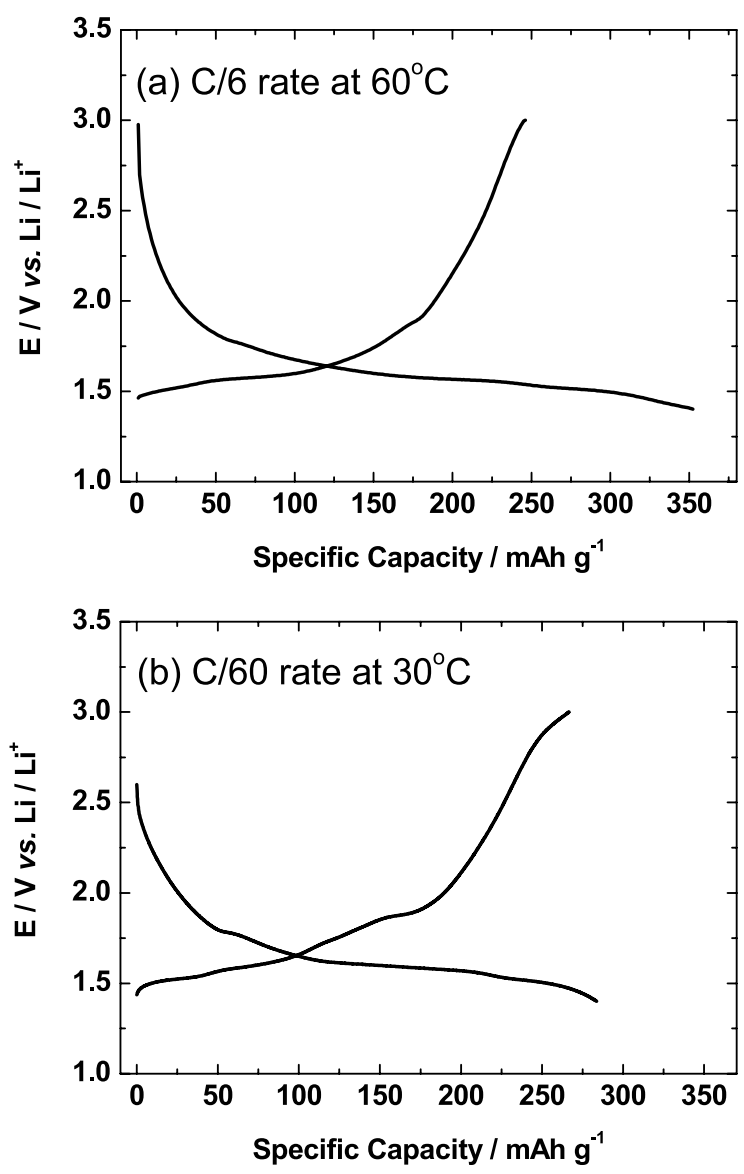

Fig. 6 Charge/discharge curves of $\mathrm{TiO}_{2}(\mathrm{~B})$ at different rates and temperatures in $1 \mathrm{M} \mathrm{LiPF}_{6} / \mathrm{EC}+\mathrm{DEC}(1: 1)$. Potential range: $1.4-3.0 \mathrm{~V}$ vs. $\mathrm{Li} / \mathrm{Li}^{+}$. (a) $\mathrm{C} / 6,60{ }^{\circ} \mathrm{C}$; (b) $\mathrm{C} / 60$, $30{ }^{\circ} \mathrm{C}$.
$\mathrm{K}_{2} \mathrm{Ti}_{4} \mathrm{O}_{9}$ precursor by ion-exchange and dehydration. $\mathrm{Li}^{+}$ ion insertion/extraction properties of the $\mathrm{TiO}_{2}(\mathrm{~B})$ sample as a high-potential negative electrode were investigated, aiming at reducing the irreversible capacity and improving the reversible capacity. The irreversible capacity

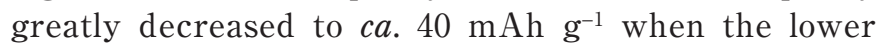
potential limit was set at $E \geq 1.2 \mathrm{~V}$. This indicated that the irreversible capacity mainly originated from surface reactions, such as solvent decomposition, at $E \leq 1.2 \mathrm{~V}$ in the first cycle. Raising the lower potential limit to 1.2-1.4 $\mathrm{V}$ also improved the cycleability of $\mathrm{TiO}_{2}(\mathrm{~B})$, but brought about a trade-off of a reduction in reversible capacity (to ca. $170 \mathrm{mAh} \mathrm{g}^{-1}$ ).

In galvanostatic intermittent titration tests, large polarization was observed at the beginning and the end of charging. This clearly indicated that a slow process is involved in the insertion reaction at the beginning and the end of charging, which causes solvent decomposition at potentials lower than $1.4 \mathrm{~V}$ at the end of charging. It is therefore important to improve the reaction rate, in particular, at the end of charging. In fact, the reversible capacity was greatly improved to 246 and $276 \mathrm{mAh} \mathrm{g}^{-1}$ at an elevated temperature of $60^{\circ} \mathrm{C}$ and at a lower rate of $\mathrm{C} / 60$, respectively. In addition, an obscure potential plateau, which is assigned to the anatase phase, appeared on the charge and discharge profile at a low rate of $\mathrm{C} / 60$. The $\mathrm{TiO}_{2}(\mathrm{~B})$ sample contained $c a$. $14 \%$ of the anatase phase as an impurity, and a reduction of the anatase phase was found to be effective for an increase in reversible capacity at moderate charge/discharge rates.

\section{References}

1) B. Scrosati, Nature, 373, 557 (1995).

2) G. Armstrong, A. R. Armstrong, J. Canales, and P. G. Bruce, Electrochem. Solid State Lett., 9, A139 (2006).

3) A. R. Armstrong, G. Armstrong, J. Canales, and P. G. Bruce, Angew. Chem., Int. Ed., 43, 2286 (2004).

4) A. R. Armstrong, G. Armstrong, J. Canales, R. Garcia, and P. G. Bruce, Adv. Mater., 17, 862 (2005).

5) A. R. Armstrong, G. Armstrong, J. Canales, and P. G. Bruce, J. Power Sources, 146, 501 (2005).

6) H. Zhang, G. R. Li, L. P. An, T. Y. Yan, X. P. Gao, and H. Y. Zhu, J. Phys. Chem. C, 111, 6143 (2007).

7) L. P. An, X. P. Gao, G. R. Li, T. Y. Yana, H. Y. Zhub, and P. W. Shen, Electrochim. Acta, 53, 4573 (2008).

8) M. Inaba, Y. Oba, F. Niina, Y. Murota, Y. Ogino, A. Tasaka, and K. Hirota, J. Power Sources, 189, 580 (2009).

9) T. P. Feist and P. K. Davies, J. Solid State Chem., 101, 275 (1992).

10) T. Ohzuku, A. Ueda, and N. Yamamoto, J. Electrochem. Soc., 142, 1431 (1995).

11) K. M. Colbow, J. R. Dahn, and R. R. Haering, J. Power Sources, 26, 397 (1989).

12) K. Zaghib, M. Simoneau, M. Armand, and M. Gauthier, J. Power Sources, 81, 300 (1999).

13) J. R. Smith, F. C. Walsh, and R. L. Clarke, J. Appl. Electrochem., 28, 1021 (1998).

14) M. Zukalova, M. Kalbac, L. Kavan, I. Exnar, and M. Gaetzel, Chem. Mater., 17, 1248 (2005). 